\title{
Tensile and Fatigue Behavior of Superelastic Shape Memory Rods
}

\author{
Jason Treadway ${ }^{\dagger}$, Ali Abolmaali ${ }^{\dagger \dagger}$, Frank $\mathrm{Lu}^{\dagger \dagger \dagger}$ and Pranesh Aswath ${ }^{\dagger \dagger \dagger}$ \\ $\uparrow$ Former Graduate Student, Materials Science and Engineering Department \\ $\dagger \dagger$ Professor, Civil and Environmental Engineering Department \\ $\dagger \dagger \dagger$ Professor, Mechanical and Aerospace Engineering Department \\ $\uparrow \dagger \uparrow \uparrow$ Professor, Materials Science and Engineering Department \\ University of Texas at Arlington, Arlington, TX 76019
}

Contact Author: Dr. Pranesh Aswath, Materials Science and Engineering Department, 500 West First Street, Rm. 325, University of Texas at Arlington, Arlington, TX, 76019. Email: aswath@uta.edu, Phone: 817-272-0308,Fax: 818-272-2538 


\section{$\underline{\text { Abstract }}$}

The tensile and fatigue behavior of superelastic shape memory alloy (SMA) bars heattreated at three different temperatures were examined. Low cycle fatigue tests at variable load rates were carried out to determine the effect of stress and frequency on residual strain and energy dissipation in a fatigue cycle. The mechanism of energy dissipation was studied by monitoring the temperature changes in the fatigued samples as a function of applied stress and frequency of testing. Results from the tensile tests revealed that the stress for the Austenite to Martensite transformation decreased from 408 MPa to 204 $\mathrm{MPa}$ with an increase in temperature of heat treatment from 300 to $450^{\circ} \mathrm{C}$. The ultimate strength of the SMA increased from $952 \mathrm{MPa}$ to $1115 \mathrm{MPa}$ when the heat treatment temperature was increased from 300 to $450^{\circ} \mathrm{C}$. Fatigue testing prior to conducting the tensile test decreased the ultimate strength of the SMA and also reduced the failure strain. The energy dissipation in fatigue tests was found to decrease as test frequency increased from $0.025 \mathrm{~Hz}$ to $0.25 \mathrm{~Hz}$ and the change in sample temperature during the test at the lower test frequency was found to be considerably higher than at the higher frequency.

Keywords: Superelastic alloys, Nickel Titanium, Fatigue, Fracture, Mechanical Properties. 


\subsection{Introduction}

Earthquakes in Kobe, Japan (1995) and Northridge, USA (1994) have brought into stark focus the need for structures to be more energy absorbing during seismic events [1,2]. Shape memory alloys are a class of intermetallic alloys that have unique mechanical properties characterized by two effects. The shape memory effect (SME) describes the ability of the material to recover from plastic deformation through thermal processing. The second effect relates to the materials ability to recover from large elastic strains (up to $8 \%$ ) as is termed superelasticity effect (SE). The early work on shape memory alloys focused on getting a fundamental understanding of the thermodynamics and mechanism of the phase transformations involved [3]in the SME and SE effects [418] A number of researchers have investigated the feasibility of incorporating superelastic shape memory alloys into smart structures for seismic resistance or damage tolerant structures [19-23] . In addition NiTi SMA's find application in medical applications such as orthodontics and maxillofacial surgeries [24-28] , in aerospace and space applications as actuators and sensors [29-33] . A recent review paper detailed a comprehensive account on the development and application of shape memory alloys [34]

\subsection{The Shape Memory Effect}

Shape memory effect (SME) describes the ability to restore the original shape of a plastically deformed sample through the application of a thermal process $[4,5,10,35-37]$. This phenomenon results from a crystalline phase change known as thermoelastic martensitic transformation. At temperatures below the martensitic finish, $M_{f}$, temperature, 
the alloy is in a martensitic phase and self accommodating twins characterizes the microstructure. If stress is applied, deformation proceeds by twin boundary movement resulting in a detwinned martensitic microstructure. Upon heating the material to a temperature above its austenite finish, $A_{f}$, temperature, the alloy returns to its parent austenitic phase and deformation is recovered.

\subsection{The Superelasticity Effect}

The superelasticity effect (SE) refers to the ability of a material to return to its original shape upon unloading after substantial deformation [5,38-41]. At temperatures above the austenite finish, $A_{f}$, temperature, the material is in its parent austenitic phase and the atomic structure is a simple cubic lattice. As a load is applied to the material, a stress-induced phase change results and the material undergoes a solid-state phase transformation from austenite to detwinned martensite. Since the detwinned martensitic phase transformation is stress induced, removal of the applied load causes the material to return to its parent austenitic phase. From an atomic point of view, the cubic austenite lattice undergoes a shear-like strain due to the applied stress, resulting in an unstable detwinned martensitic structure. Upon removal of the applied stress, the crystalline lattice returns to its original cubic structure.

\subsection{Stress-Strain Comparison of Shape Memory and Superelasticity Effects}

A comparison of the stress-strain curves for the SME and SE is presented in Figure 1. The curve on the left hand side of the figure illustrates the SME. It is seen here that as stress is applied to the material, detwinning occurs at a critical stress level and 
remains almost constant throughout the detwinning process. Conversely, the strain increases rapidly upon reaching the critical stress. Unloading of the sample at any point after the critical stress level is reached results in residual strain. However, if the sample is subjected to a heat treatment above the $A_{f}$ temperature, the residual strain is recovered. The figure on the right graphically represents the SE effect. In this figure there are three distinct areas of interest. First is the initial stiffness of the material that represents the austenite modulus. At a critical stress level, the curve departs from initial linearity and reaches a plateau. This stress plateau signifies the forward transformation from austenite to martensite. Once the material has fully transformed to martensite the curve sharply turns upward representing the martensite stiffness. Unloading at this secondary transition stress results in a reverse transformation from martensite to austenite and the deformation is fully recovered. The hysterisis curve generated by the forward and reverse transformations is representative of the energy dissipated by the system. The energy dissipation coupled with the recentering ability of the material plays a key role in our selection of SMA's as possible materials for seismic resistant and damage tolerant structures. Further, it is important to note that the critical stress level in the austenite to martensite transformation of the SE curve is greater than the critical stress level for twinned to detwinned martensite in the SME curve.

\subsection{Nickel-Titanium Based Shape Memory and Superelastic Alloys}

The equiatomic intermetallic compound of nickel and titanium forms the basis for the NiTi alloy family. This system is unique because it has a moderate solubility range for excess nickel or titanium as well as other alloying elements and it exhibits ductility comparable to most common alloys. A solubility in the NiTi phase on the nickel- rich 
side of the diagram extends from 50 to 57 atomic percent over a temperature range of 660 to $1140{ }^{\circ} \mathrm{C}$. The importance of this solubility gradient is that it allows alloying with different elements to modify the mechanical as well as the transformation properties of the alloy. Alloying with excess nickel is often used to suppress the transformation temperature and to increase the yield strength of the austenite. It has been observed that the $M_{s}$ temperature changes more than $100^{\circ} \mathrm{K}$ for a 1 atomic percent change in composition. Additional alloying elements commonly used in this system include iron and chromium that lower the transformation temperature, and copper which is used to decrease the hystersis and lower the deformation stress of the martensite [42] . However, use of more than 9 at.\% Fe is detrimental as it increases the possibility of stress corrosion cracking of NiTi [43-45] . Atomistic modeling studies have indicated that additives such as $\mathrm{Fe}, \mathrm{Pt} . \mathrm{Pd}, \mathrm{Au}, \mathrm{Al}, \mathrm{Cu}, \mathrm{Zr}$ and $\mathrm{Hf}$ bind tightly with Ti forming ordered structures [46] . When $\mathrm{Nb}$ is added in larger quantities (typically $>5$ at. \%) it partitions as a pure $\mathrm{Nb}$ phase which yields easily and absorbs the energy of deformation in the structure [47,48] . Contaminants such as oxygen and carbon have a detrimental effect and tend to shift the transformation temperature and degrade the mechanical properties of the alloy and should be minimized $[49,50]$. The NiTi system is interesting because the material properties of the alloy can be improved by utilizing various diffusional and diffusionless phase transformations.

The fatigue behavior of SMA's has been studied by several researchers examining the fatigue crack growth behavior near the threshold for crack growth [51] as well as in the Paris regime [52] . McKevey et.al.'s [52] work on fatigue crack growth has indicated that the resistance to crack growth in the fully martensitic phase is better than in 
the superelastic temperature regime. On the other hand increasing the mean strain prolongs fatigue life in the superelastic NiTi when more stress induced martensite is present [53]. In addition low and high cycle fatigue behavior of Superelastic NiTi wire and hollow tube have been studied by Matsui and co-workers [54] who showed that fatigue behavior of high elastic thin wires were independent of temperature and frequency of testing. The martensite transformation stress in superelastic thin wires and thin hollow tubes increased in proportion to test temperature and frequency of testing [54] A study examining the role of heat treatment temperature between 350 and $500^{\circ} \mathrm{C}$ on fatigue behavior of NiTi tubing was conducted by Lopes et. al. [55] . Results indicate that fatigue tests conducted at a mean strain of $1.5 \%$ with alternating strain of $0.2-0.4 \%$ indicated a plateau in the stress-strain plots for all heat treatment temperatures below $450^{\circ} \mathrm{C}$ indicating super elastic deformation in fatigue loading [55] .

Much of the work in literature on mechanical properties of NiTi alloys has been conducted on wires, sheets and other small cross section specimens. In this study we explore the role of heat treatment temperature on the Austenite to Martensite transformation stress as well as the ultimate strength and ductility of NiTi rods. In addition the low cycle fatigue behavior within the superelastic range is also examined for the different heat treatments and its influence on the subsequent tensile behavior is studied.

\subsection{Experimental Procedure}

\subsection{Materials Selection and Machining}

The NiTi alloy chosen for this study was $12.5 \mathrm{~mm}$ Nitinol bar comprised of 55.89 wt.\% nickel and 44.11 wt.\% titanium. It was hot rolled, straightened and centerless 
ground by the manufacturer with an as received hardness of $38 \mathrm{HRC}$. Figure 2 shows the dimensional properties of the machined tensile sample that conform to ASTM Standard E08-01 requirements.

\subsection{Heat Treatment}

Post machining heat treatment was required to set the superelasticity effect of the NiTi samples. For each heat treatment a thermocouple was attached to the sample to ensure proper temperature was maintained throughout the process. Three initial heat treatment temperatures were chosen ranging from 300 to $450^{\circ} \mathrm{C}$. Time at temperature was 1.5 hours per sample followed by a water quench.

\subsection{Test Set-up and Protocol}

Both tensile and cyclic tests were performed on an MTS 810 materials testing system consisting of the following components: 1) 100 kip load cell, 2) LVDT, 3) MTS 458.20 Microconsole, 4) MTS 458.91 Microprofiler and 5) MTS 647 Hydraulic Wedge Grips. An Epsilon 3542 extensometer with 50\% tensile travel and 20\% compressive travel was used to measure strain values. Temperature was measured using an Omega type-J thermocouple mounted to the specimen surface.

The tensile tests were run in displacement control at a constant rate of 2.85 $\mathrm{mm} /$ minute $(0.1125$ inch/minute $)$ crosshead movement in accordance with ASTM Standard E08-01. Cyclic testing were performed in load control at $0.025 \mathrm{~Hz}$ and $0.25 \mathrm{~Hz}$ frequencies using a load-strain correlation determined by baseline tensile test on first run (non-fatigued) specimens. Careful consideration was made in choosing a load value that 
corresponded to the desired strain levels of 1,2,3,4,5 and 6 percent strain for each heat treatment temperature. Cycles corresponding to 1 though 5 percent strain were performed once whereas the 6 percent strain cycle was repeated one hundred times. The 6 percent strain was chosen as the upper strain limit corresponding to the maximum superelastic strain. Figure 3 shows an idealized load protocol for the static cyclic tests including 1-6 percent strain cycles and the first five of one hundred 6 percent cycles.

\subsection{Results and Discussion}

Throughout this section the following nomenclature HTxxx will be used to differentiate the particular heat treatment used and the order the test was conducted. Specifically, xxx refers to the heat treatment, namely 300,350 or 450 degrees ${ }^{\circ} \mathrm{C}$.

\subsection{Tensile Tests}

Results from the tensile tests on non-fatigued rods are shown in Figure 4. The results show good repeatability for each of the two tests performed on both the 300 and $350{ }^{\circ} \mathrm{C}$ heat treated samples. It can also be seen that the heat treatment temperature affects the transformation stress (Austenite to Martensite) and the tensile strength. The sample heated treated at $300^{\circ} \mathrm{C}$ has the highest transformation stress, but a lowest tensile strength. Conversely, the $450^{\circ} \mathrm{C}$ sample has the lowest transformation stress and the highest ultimate stress. The transformation stress for each heat treatment was 204, 340 and $408 \mathrm{MPa}$, for the HT450, HT350, and HT300 samples respectively. Similarly, the ultimate stress for each sample was 1115, 1033 and $952 \mathrm{MPa}$ for the samples in descending order of heat treat temperature. Clearly, a trend is established giving rise to an inverse relationship between heat treatment and transformation stress and a direct 
correlation between temperature and tensile strength. This is shown in Figure 5 that maps the transformation stress and ultimate tensile strength as a function of heat treatment condition. On the other hand, failure strain appears to be consistent for all temperature ranges. In addition, the modulus of elasticity for the austenite phase is consistent for each heat treatment temperature.

Figure 6 shows the results of the tensile tests performed on the fatigued samples. Comparing these results to those of the non-fatigued samples indicate that the transformation stress and ultimate stress decrease as the sample is fatigued for both the HT300 and HT350 samples. This is in agreement with other studies in super elastic NiTi alloys by DesRoches et. al. [56], Dolce and Cardone [57] and Strandel et. al. [58] . The transformation stress is not well defined for the HT450 sample and effectively disappears. The disappearance of the superelasticity effect is a result of large residual strains induced during cyclic testing in the sample heat treated at $450^{\circ} \mathrm{C}$. Ultimate strength for the HT450, HT350 and HT300 samples after fatigue cycling was 1071, 1020 and $901 \mathrm{MPa}$ respectively. Similarly, the ultimate strain was $6.0,15.5$ and $24.5 \%$ for the HT450, HT350 and HT300 samples respectively.

\subsection{Cyclic testing}

Cyclic fatigue tests were conducted at frequencies of 0.025 and $0.25 \mathrm{~Hz}$. Figures 7(a,b,c) show the stress-strain hysterisis loops for the 1,2, 3, 4, 5 and 6 percent strain cycles conducted at $0.025 \mathrm{~Hz}$ for the three heat treatment conditions of 300,350 and $450^{\circ} \mathrm{C}$. The fatigue cycles shown in detail in Figure 8(a,b) correspond to the 1, 10, 25, 50, 75 and 100 cycles at the 6 percent strain level. This is done to illustrate the effect of cycling on 
residual strain accrual and energy dissipation. The hystersis loops generated for the HT300 and HT350 samples show good energy dissipation characteristics with minimal, $<1.2$ percent, strain accrual at the $100^{\text {th }} 6$ percent strain cycle. By contrast, the HT450 sample shows a rapid increase in residual strain beginning at the 1 percent cycle with an accumulation of 4.5 percent residual strain by tests end. Similarly, the energy dissipation of the HT450 sample is negligible as compared to the HT300 and HT350 samples. This is largely due to the fact that the HT450 has virtually no superelasticity under fatigue loading. Table 3 shows the energy dissipation per cycle for the HT300 and HT350 cycles. The energy dissipation was calculated by curve fitting a sixth order polynomial equation to the forward and reverse phase transformation curves and integrating over the appropriate limits. The area under the reverse curve was then subtracted from the forward curve to determine the energy dissipation per cycle. Reasonable repeatability is found between the tests within the respective HT300 and HT350 heat treatment temperatures. The maximum energy dissipation occurs at the first $6 \%$ strain cycle and decreases as the material is cycled through the hundredth $6 \%$ cycle. Comparing the two heat treatment temperatures, the HT350 samples show the larger amount of energy dissipation.

Second sets of cyclic tests were performed at a higher frequency $(0.25 \mathrm{~Hz})$ and the results of the tests are shown in Figure 9. The hysteresis loops for 1, 2, 3, 4, 5, 6 and 6-10 percent cycles are shown. As a result of the higher frequency the desired 6 percent maximum strain level was not achieved since the loading protocol from the previous cyclic tests at the lower frequency $(0.025 \mathrm{~Hz})$ were repeated for the higher frequency tests. Therefore, the desired upper end loads were not achieved resulting in a lower than desired strain. Consequently, the hystersis loops for the higher frequency tests $(0.25 \mathrm{~Hz})$ 
are not as large as compared to the lower frequency tests $(0.025 \mathrm{~Hz})$. In comparison, the HT350 sample appears to have a larger hystersis loop than the HT300 sample and therefore shows better energy dissipation. Nonetheless, a reasonable assumption can be made from the hystersis loops that sample testing at the higher frequency results in lower energy dissipation per cycle which confirms the kinetics inherent in the forward and reverse phase transformation process.

\subsection{Load-Temperature Relationship}

During cyclic testing that the temperature of the specimen increased on the tensile portion of the cycle and decreased on the compressive portion. HT300 samples were tested at a frequency of $0.25 \mathrm{~Hz}$ and the HT350 samples were tested at 0.25 and $0.025 \mathrm{~Hz}$ respectively. Tables 1 through 3 show the results of these tests for $6 \%-1,6 \%-10,6 \%-20$, $6 \%-40,6 \%-60,6 \%-80$ and 6\%-100 fatigue cycles identifying low and high temperature, change in temperature, energy dissipation and percent strain.

The HT350-0.025 Hz sample shows the most dramatic change in temperature with a $\Delta \mathrm{T}$ of approximately $21^{\circ} \mathrm{C}$ and a maximum energy dissipation of $7.3 \mathrm{~N} . \mathrm{m}\left(65 \mathrm{lb}_{\mathrm{f}^{-}}\right.$ in). Figure 10(a) shows a plot of the first 5 cycles of the fatigue test corresponding to 1 through 5 percent strain cycles as well as the first ten 6 percent cycles. Here it is shown that the sample begins to heat during tensile loading and cool during the compressive cycle. However, most interesting is the sample begins to cool below ambient temperature as the part is cycled reaching a constant low temperature at approximately the tenth 6 percent strain cycle. In addition, the energy dissipation also decreases which indicates a correlation with change in sample temperature. The last 5 cycles of the test are shown in 
figure 10(b). It is shown here that the temperature effect has stabilized for both the tension and compression cycles. The exothermic (forward phase) and endothermic reaction (reverse phase) agree with the findings presented by Tobushi et. al. [59] .

The higher frequency tests performed on the HT300 and HT350 samples also exhibit a heating effect during tensile loading and cooling during compressive loading, but the temperature differential is not as significant as was observed in the lower frequency tests. Likewise, the higher frequency tests do not exhibit as much energy dissipation as the lower frequency test. One possible explanation is that since the forward and reverse austenite-martensite transformation is time dependent, the material may not have enough time to fully recover to its original austenite phase resulting in residual martensite within the lattice. In addition, the percent strain achieved during cyclic testing was higher for the low frequency tests (approximately 6 percent), whereas a maximum of 5.1 and 4.5 percent for the HT300 and HT350 samples respectively was achieved. Tables 2 and 3 show the temperature difference and energy dissipation for the HT350 and HT300 samples fatigued at $0.25 \mathrm{~Hz}$.

\subsection{Fracture Behavior of Superelastic NiTi Shape Memory Alloys}

Samples that were heat treated at 300,350 and $450^{\circ} \mathrm{C}$ and fatigued for 100 cycles at a maximum strain of $6 \%$ were subsequently tensile tested. The fracture surfaces of these tensile failures were examined using secondary electron imaging in a scanning electron microscope. Figures 12, 13 and 14 show low magnification and localized high magnification images of the fracture surfaces for the 300,350 and $450^{\circ} \mathrm{C}$ heat treated samples that were fatigued and subsequently tensile tested. Following the chevron pattern 
back to the origin can identify the origin of the fracture. Macroscopically in three cases we can see that the fracture surface is relatively flat and has small undulations characteristics of a relatively brittle fracture. The extent of surface roughness increases with heat treatment temperature with the $450^{\circ} \mathrm{C}$ heat treat samples having the largest roughness. In each individual case, the rate of fracture propagation increases from the origin to the final fracture and is reflected in the nature of fracture surface. At origin of the fracture in the $300^{\circ} \mathrm{C}$ heat treat sample the fracture surface exhibits quasi-cleavage fracture with ductile tear ridges at the boundaries of the cleavage facets. The transgranular cleavage facet size increases as the fracture propagation rate increase with the larger facets seen towards final fracture. In comparison the fracture surface of the $350^{\circ} \mathrm{C}$ heat treated sample shows smaller cleavage facet size both at the fracture origin and at final fracture coupled with a larger fraction of ductile tear ridges at the boundaries of the cleavage facets. This difference in the fracture mode is reflected in the ductility of the sample where, the ductility of the $350^{\circ} \mathrm{C}$ heat treat sample after fatigue is $25 \%$ strain to failure while the $300^{\circ} \mathrm{C}$ heat treat sample is approximately $17 \%$. The $450^{\circ} \mathrm{C}$ heat treated sample exhibits significant strain accumulation during the fatigue process and the austenite to martensite transformation is suppressed on subsequent tensile testing. The fracture ductility of the $450^{\circ} \mathrm{C}$ is $6 \%$ after fatigue compared to $25 \%$ prior to fatigue. The fracture surface shown in Figure 13 indicates much larger cleavage facets with smaller tear ridges indicative of lower energy absorption prior to failure.

\subsection{Conclusion}

Heat treatment temperature plays an important role in the mechanical properties of superelastic shape memory alloys. Specifically, an increase in heat treatment temperature 
from 300 to $450^{\circ} \mathrm{C}$ results is an increase in tensile strength and a decrease in transformation stress. Heat treatment temperature above $450{ }^{\circ} \mathrm{C}$ was also found to negate the superelasticity effect for the NiTi alloy studied. In addition, fatigue cycling was found to lower the Austenite to Martensite transformation stress and the ultimate strength, and it also lowers the ultimate strain to failure of the superelastic NiTi alloy. Frequency of fatigue testing was found to have an effect on energy dissipation per cycle resulting in higher energy dissipation at the lower frequency. During cyclic testing the sample temperature was found to increase during the loading part of the fatigue cycle reflective of the exothermic transformation from Austenite to Martensite and a drop in temperature on the unloading part of the fatigue cycle reflective of the endothermic transformation from Martensite to Austenite. This study provides a framework to design heat treatments of super elastic NiTi rods where in the energy dissipation, transformational stress and strain to failure in the alloy may be optimized. This is of critical importance in applications such as seismic retrofits of bridges wherein low frequency by high loads are possible and energy dissipation is of critical importance coupled with recovery of original shape.

Acknowledgements: Support from NSF under grant \# 0243994 is gratefully acknowledged. Maching support provided by Renaissance Machine Company of Ft. worth is gratefully appreciated. Assistance in mechanical testing provided by Dr. Emily McCarthy, Mr. Cory Knight and Mr. Byron Webb is gratefully acknowledged. 


\section{References}

[1] Mitchell D, Bruneau M, Williams M, Anderson D, Saatcioglu M, Sexsmith R. Performance of bridges in the 1994 Northridge earthquake. Canadian journal of civil engineering $1995 ; 22: 415-27$.

[2] Ghannoum WM, Moehle JP, Bozorgnia Y. Analytical collapse study of lightly confined reinforced concrete frames subjected to northridge earthquake ground motions. J Earthquake Eng 2008;12:1105-19.

[3] Abolmaali A, Treadway J, Aswath P, Lu FK, McCarthy E. Hysteresis behavior of t-stub connections with superelastic shape memory fasteners. Journal of Constructional Steel Research 2006;62:831-8.

[4] Otsuka K, Wayman CM. Shape memory materials. : Cambridge University Press, 1999.

[5] OTSUKA K, SAWAMURA T, SHIMIZU K, WAYMAN CM. Characteristics of the martensitic transformation in TiNi and the memory effect. 1971;2:2583-8.

[6] Buehler WJ, Wiley RC, Gilfrich JV. Effect of Low-Temperature Phase Changes on Mechanical Properties of Alloys Near Composition Tini. J Appl Phys 1963;34:1475.

[7] Rozner AG, Heintzel.Ef, Buehler WJ, Gilfrich JV. Effect of Addition of Oxygen Nitrogen and Hydrogen on Microstructure and Hardness of Cast Tini Intermetallic Compound. Asm Transactions Quarterly 1965;58:415.

[8] Bilby BA, Christian JW. Martensitic Transformations. Uspekhi Fizicheskikh Nauk 1960;70:515-64.

[9] Wayman CM. Introduction to the crystallography of martensitic transformations. : Macmillan, 1964.

[10] Wayman CM, Shimizu K. SHAPE MEMORY ( MARMEM ) EFFECT IN ALLOYS. Metal Science Journal 1972;6:175-83.

[11] Nishiyama Z. Martensitic transformation. : Academic Press, 1978.

[12] Warlimont H, Delaey L. Progress in materials science. Martensitic transformations in copper-, silver-, and gold-based alloys. 1974.

[13] Khachaturian AG. Theory of structural transformations in solids. 1983.

[14] Christian JW. The theory of transformations in metals and alloys (part I II). : Access Online via Elsevier, 2002.

[15] Bhattacharya K. Microstructure and Martensite: Why it Forms and how it Gives Rise to the Shape-memory Effect. : Oxford University Press, 2003. 
[16] Machado G, Louche H, Alonso T, Favier D. Superelastic cellular NiTi tube-based materials: Fabrication, experiments and modeling. Materials and Design 2015;65:212-20.

[17] Kucharski S, Levintant-Zayonts N, Luckner J. Mechanical response of nitrogen ion implanted NiTi shape memory alloy. Materials and Design 2014;56:671-9.

[18] Yang D, Jiang HC, Zhao MJ, Rong LJ. Microstructure and mechanical behaviors of electron beam welded NiTi shape memory alloys. Materials and Design 2014;57:21-5.

[19] DesRoches R, Delemont M. Seismic retrofit of simply supported bridges using shape memory alloys. Eng Struct 2002;24:325-32.

[20] Ocel J, DesRoches R, Leon RT, Hess WG, Krumme R, Hayes JR et al. Steel beam-column connections using shape memory alloys. J Struct Eng 2004;130:732-40.

[21] Saadat S, Salichs J, Noori M, Hou Z, Davoodi H, Bar-on I et al. An overview of vibration and seismic applications of NiTi shape memory alloy. Smart Mater Struct 2002;11:218-29.

[22] Saadat S, Noori M, Davoodi H, Hou Z, Masuda A. Optimal NiTi hybrid tendon system for structural vibration control. 2001;4331:209-17.

[23] Song G, Ma N, Li H-. Review of Applications of Shape Memory Alloys in Civil Structures. 2004:559-66.

[24] Es-Souni M, Es-Souni M, Fischer-Brandies H. Assessing the biocompatibility of NiTi shape memory alloys used for medical applications. Analytical and Bioanalytical Chemistry 2005;381:557-67.

[25] Gil FJ, Planell JA. Shape memory alloys for medical applications. Proc Inst Mech Eng Part H J Eng Med 1998;212:473-88.

[26] Raboud DW, Faulkner MG, Lipsett AW. Superelastic response of NiTi shape memory alloy wires for orthodontic applications. Smart Mater Struct 2000;9:684-92.

[27] Schetky LM. Industrial applications of shape memory alloys in North America. Mater Sci Forum 2000;327:9-16.

[28] Takaoka S, Horikawa H, Kobayashi J, Shimizu K. Applications and development of shapememory and superelastic alloys in Japan. 2002;394-395:61-8.

[29] Chau ETF, Friend CM, Allen DM, Hora J, Webster JR. A technical and economic appraisal of shape memory alloys for aerospace applications. Materials Science and Engineering A 2006;438-440:589-92.

[30] Epps JJ, Chopra I. Methodology for in-flight tracking of helicopter rotor blades using shape memory alloy actuators. Journal of the American Helicopter Society 2004;49:192-200.

[31] Godard OJ, Lagoudas MZ, Lagoudas DC. Design of Space Systems Using Shape Memory Alloys. 2003;5056:545-58. 
[32] Singh K, Sirohi J, Chopra I. An improved shape memory alloy actuator for rotor blade tracking. J Intell Mater Syst Struct 2003;14:767-86.

[33] Strelec JK, Lagoudas DC. Fabrication and testing of a shape memory alloy actuated reconfigurable wing. 2002;4701:267-80.

[34] Jani JM, Leary M, Subic A, Gibson MA. Materials and Design. JOURNAL OF MATERIALS $\{\backslash \&\}$ DESIGN 2014;56:1078-113.

[35] Otsuka K, Ren X. Physical metallurgy of Ti-Ni-based shape memory alloys. Prog Mater Sci 2005;50:511-678.

[36] McNichols Jr. JL, Brookes PC, Cory JS. NiTi FATIGUE BEHAVIOR. J Appl Phys $1981 ; 52: 7442-4$.

[37] Shaw JA, Kyriakides S. Thermomechanical aspects of NiTi. J Mech Phys Solids 1995;43:1243-81.

[38] Heller L, ittner P, Pilch J, Landa M. Factors controlling superelastic damping capacity of SMAs. Journal of Materials Engineering and Performance 2009;18:603-11.

[39] Maletta C, Falvo A, Furgiuele F, Reddy JN. A phenomenological model for superelasticity in NiTi alloys. Smart Mater Struct 2009;18.

[40] Predki W, Klonne M. Superelastic NiTi-alloys under torsional loading. 2003;112 II:807-10.

[41] Rivin EI, Sayal G, Singh Johal PR. "Giant superelasticity effect" in niti superelastic materials and its applications. J Mater Civ Eng 2006;18:851-7.

[42] Chastaing K, Vermaut P, Ochin P, Segui C, Laval JY, Portier R. Effect of $\mathrm{Cu}$ and Hf additions on $\mathrm{NiTi}$ martensitic transformation. Materials Science and Engineering $\mathrm{A}$ 2006;438-440:661-5.

[43] Chen Y, Chung Y, Wen H. Moisture-induced embrittlement mechanism for (Ni,Fe)Ti alloys. Intermetallics 2007;15:288-93.

[44] Chen Y, Chung Y, Wu D. The effect of Fe on the moisture-induced embrittlement in (Ni,Fe)Ti alloys. Intermetallics 2004;12:815-9.

[45] Zhu JH, Liu CT, Chen CH. Effect of iron additions on environmental embrittlement of NiTi-base alloys. Intermetallics 2004;12:859-68.

[46] Bozzolo G, Noebe RD, Mosca HO. Site preference of ternary alloying additions to NiTi: $\mathrm{Fe}, \mathrm{Pt}, \mathrm{Pd}, \mathrm{Au}, \mathrm{Al}, \mathrm{Cu}, \mathrm{Zr}$ and Hf. J Alloys Compounds 2005;389:80-94.

[47] Zhao LC, Duerig TW, Justi S, Melton KN, Proft JL, Yu W et al. Study of niobium-rich precipitates in a Ni-Ti-Nb shape memory alloy. Scripta metallurgica et materialia 1990;24:221-5. 
[48] Siegert W, Neuking K, Mertmann M, Eggeler G. First cycle shape memory effect in the ternary NiTiNb system. 2003;112 II:739-42.

[49] Mentz J, Bram M, Buchkremer HP, Stoever D. Improvement of Mechanical Properties of Powder Metallurgical NiTi by reduction of impurity phases. 2008:399-408.

[50] Mentz J, Frenzel J, Wagner MF-, Neuking K, Eggeler G, Buchkremer HP et al. Powder metallurgical processing of NiTi shape memory alloys with elevated transformation temperatures. Materials Science and Engineering A 2008;491:270-8.

[51] Holtz RL, Sadananda K, Imam MA. Fatigue thresholds of Ni-Ti alloy near the shape memory transition temperature. Int J Fatigue 1999;21:S137-45.

[52] McKelvey AL, Ritchie RO. Fatigue-crack growth in the superelastic endovascular stent material nitinol. Materials Research Society Symposium - Proceedings 1999;550:281-6.

[53] Morgan NB, Painter J, Moffat A. Proceedings, International Conference on Shape Memory and Superelastic Technologies 2003:303.

[54] Matsui R, Tobushi H, Furuichi Y, Horikawa H. Tensile deformation and rotating-bending fatigue properties of a highelastic thin wire, a superelastic thin wire, and a superelastic thin tube of NiTi alloys. J Eng Mater Technol Trans ASME 2004;126:384-91.

[55] Lopes TL, Gong X-, Trepanier C. Proceedings, International Conference on Shape Memory and Superelastic Technologies 2003:313.

[56] DesRoches R, Muthukumar S. Effect of pounding and restrainers on seismic response of multiple-frame bridges. J Struct Eng 2002;128:860-9.

[57] Dolce M, Cardone D. Mechanical behaviour of shape memory alloys for seismic applications 1. Martensite and austenite NiTi bars subjected to torsion. Int J Mech Sci 2001;43:2631-56.

[58] Strandel B, Ohashi S, Ohtsuka T:I, T., Miyazaki S. Cyclic stress-strain characteristics of Ti$\mathrm{Ni}$ and Ti-Ni-Cu shape memory alloys. Materials Science and Engineering 1995;A202:14856.

[59] Tobushi H, Shimeno Y, Hachisuka T, Tanaka K. Influence of strain rate on superelastic properties of TiNi shape memory alloy. Mech Mater 1998;30:141-50. 


\section{List of Tables and Figures}

Table 1 Comparison of energy dissipation for HT300 and HT350 cyclic samples. Calculated based on area within the Stress-Strain hysteresis plots. Frequency of testing is $0.025 \mathrm{~Hz}$.

Table 2 Energy dissipation and temperature change for the HT350 sample. Frequency of testing is $0.25 \mathrm{~Hz}$.

Table 3 Energy dissipation and temperature change for the HT300 sample. Frequency of testing is $0.25 \mathrm{~Hz}$.

Figure 1 Schematic stress-strain behavior of Ni-Ti showing (a) shape memory effect and (b) superelasticity effect.

Figure 2 Schematic of the tensile samples used in testing the NiTi superelastic material.

Figure 3 Schematic showing the loading profile for the fatigue tests of the NiTi superelastic alloys.

Figure 4 Stress -strain plots of NiTi superelastic alloys heat treated at 300, 350 and $450^{\circ} \mathrm{C}$. Tensile tests were conducted in the as-heat treated condition prior to any fatigue loading.

Figure 5 The Austenite to Martensite transformation stress, ultimate strength and failure strain in the $\mathrm{NiTi}$, in the as heat treated condition and after 100 fatigue cycles at a strain of $6 \%$.

Figure 6 Stress -strain plots of NiTi superelastic alloys heat treated at 300, 350 and $450^{\circ} \mathrm{C}$. Tensile tests were conducted after 100 fatigue cycles at a maximum strain of $6 \%$. 
Figure 7 Hysterisis loops of incremental strain tests where the strain was increased from $1 \%$ to $6 \%$ and the frequency of testing was $0.025 \mathrm{~Hz}$. (a) HT-300 (b) HT-350 and (c) HT-450.

Figure 8 Hysterisis loops of fatigue cycle 1 through 100 at a strain of $6 \%$ conducted at a frequency of $0.025 \mathrm{~Hz}$. (a) HT-300 (b) HT-350.

Figure 9 (a) Hysterisis loops of incremental strain tests where the strain was increased from $1 \%$ to $3.2 \%$ for the HT-300 sample at a frequency of $0.25 \mathrm{~Hz}$, superimposed is the $100^{\text {th }}$ cycle at a maximum strain of $5 \%$. (b) Hysterisis loops of incremental strain tests where the strain was increased from $1 \%$ to $3.5 \%$ for the HT-350 sample at a frequency of $0.25 \mathrm{~Hz}$, superimposed is the $100^{\text {th }}$ cycle at a maximum strain of $4.5 \%$.

Figure 10 Superposed plots of applied load and measured temperature on the surface of the sample for fatigue tests strained to a maximum strain level of $6 \%$ at a frequency of $0.025 \mathrm{~Hz}$. (a) Fatigue cycles 1-5 for HT-350 and (b) Fatigue cycles 101-105 for HT-350.

Figure 11 Temperature change as a function of energy dissipation for fatigue cycles 1 through 100 for sample HT350 tested in fatigue at a frequency of $0.025 \mathrm{~Hz}$ and a maximum strain of $6 \%$.

Figure 12 Secondary electron micrographs of the fracture surface of HT300 test sample that had been fatigued for 100 cycles at a maximum strain of $6 \%$ at a frequency of $0.025 \mathrm{~Hz}$ followed by a tensile test to failure. Shown in this figure is a low magnification micrograph showing the macroscopic features of 
fracture as well as localized high magnification images of the surface showing different regions of fracture.

Figure 13 Secondary electron micrographs of the fracture surface of HT350 test sample that had been fatigued for 100 cycles at a maximum strain of $6 \%$ at a frequency of $0.025 \mathrm{~Hz}$ followed by a tensile test to failure. Shown in this figure is a low magnification micrograph showing the macroscopic features of fracture as well as localized high magnification images of the surface showing different regions of fracture.

Figure 14 Secondary electron micrographs of the fracture surface of HT450 test sample that had been fatigued for 100 cycles at a maximum strain of $6 \%$ at a frequency of $0.025 \mathrm{~Hz}$ followed by a tensile test to failure. Shown in this figure is a low magnification micrograph showing the macroscopic features of fracture as well as localized high magnification images of the surface showing different regions of fracture. 


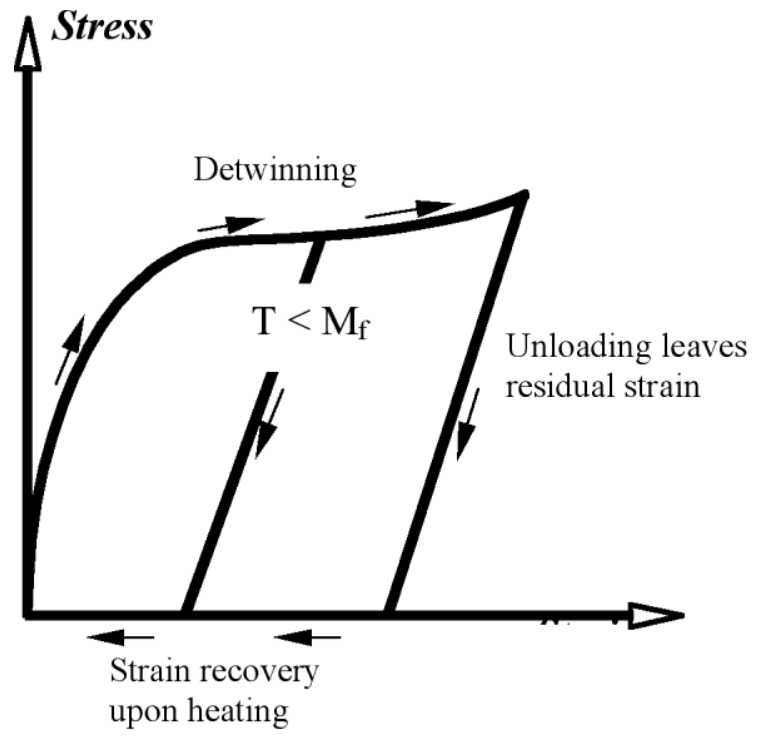

(a)

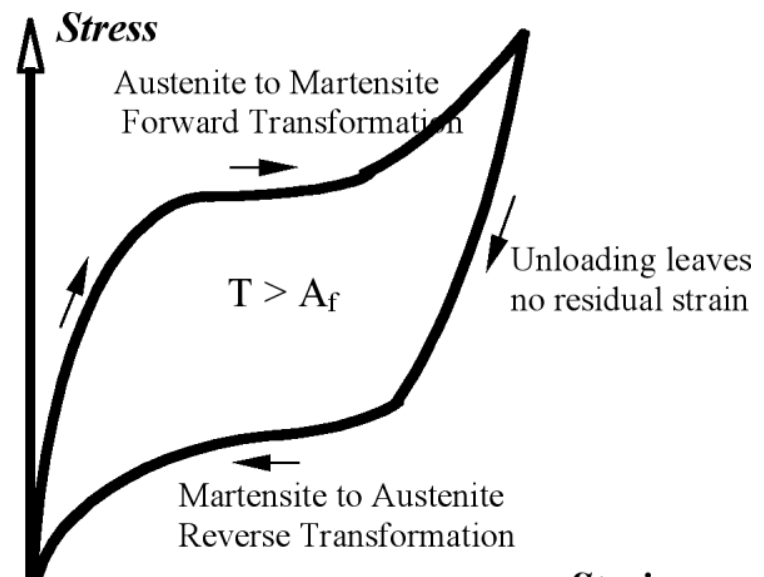

Strain

(b)

Figure 1 


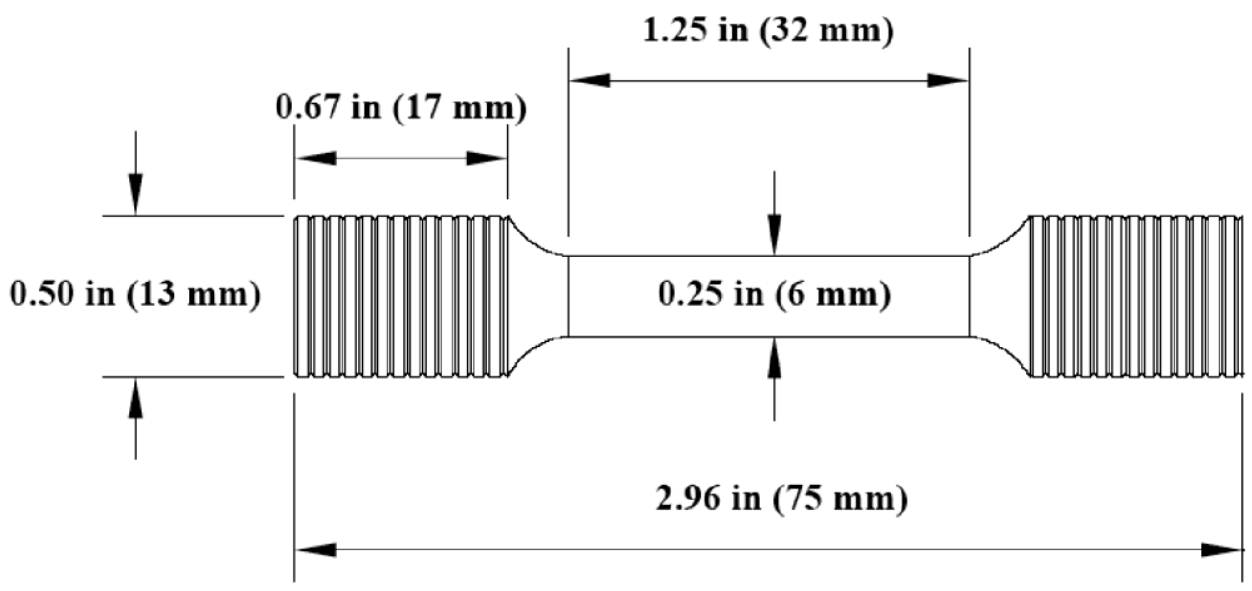

Figure 2 


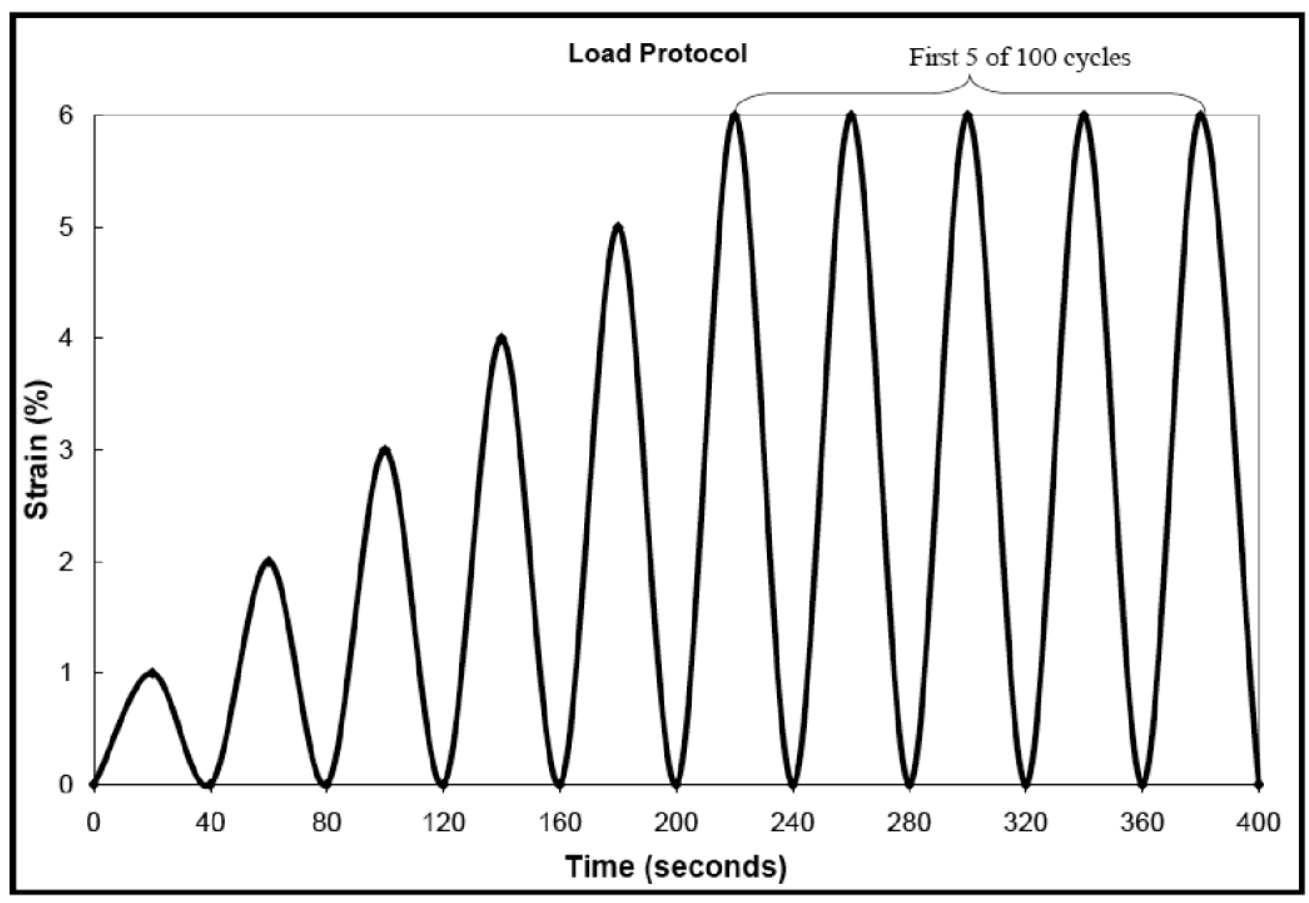

Figure 3 


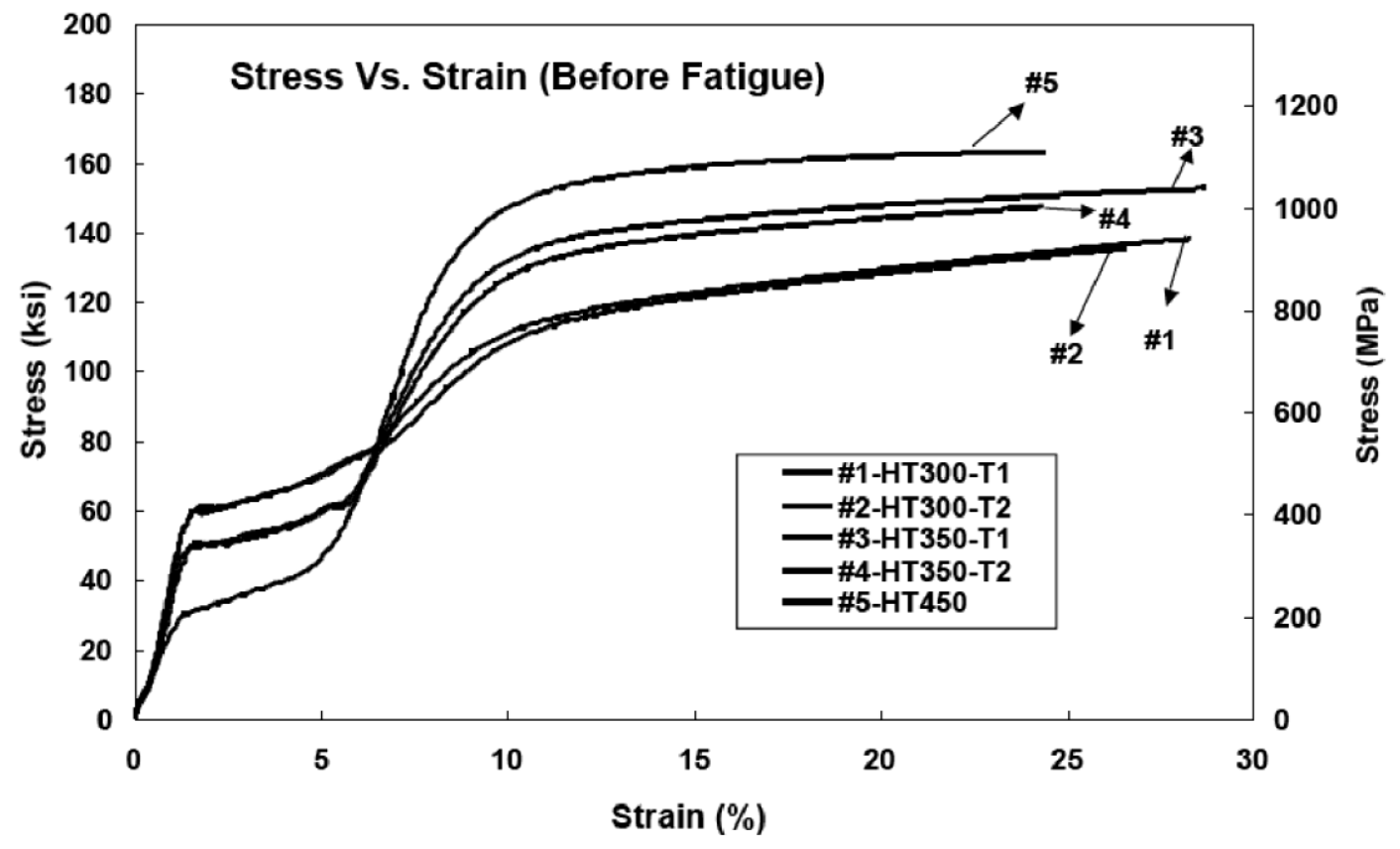

Figure 4 


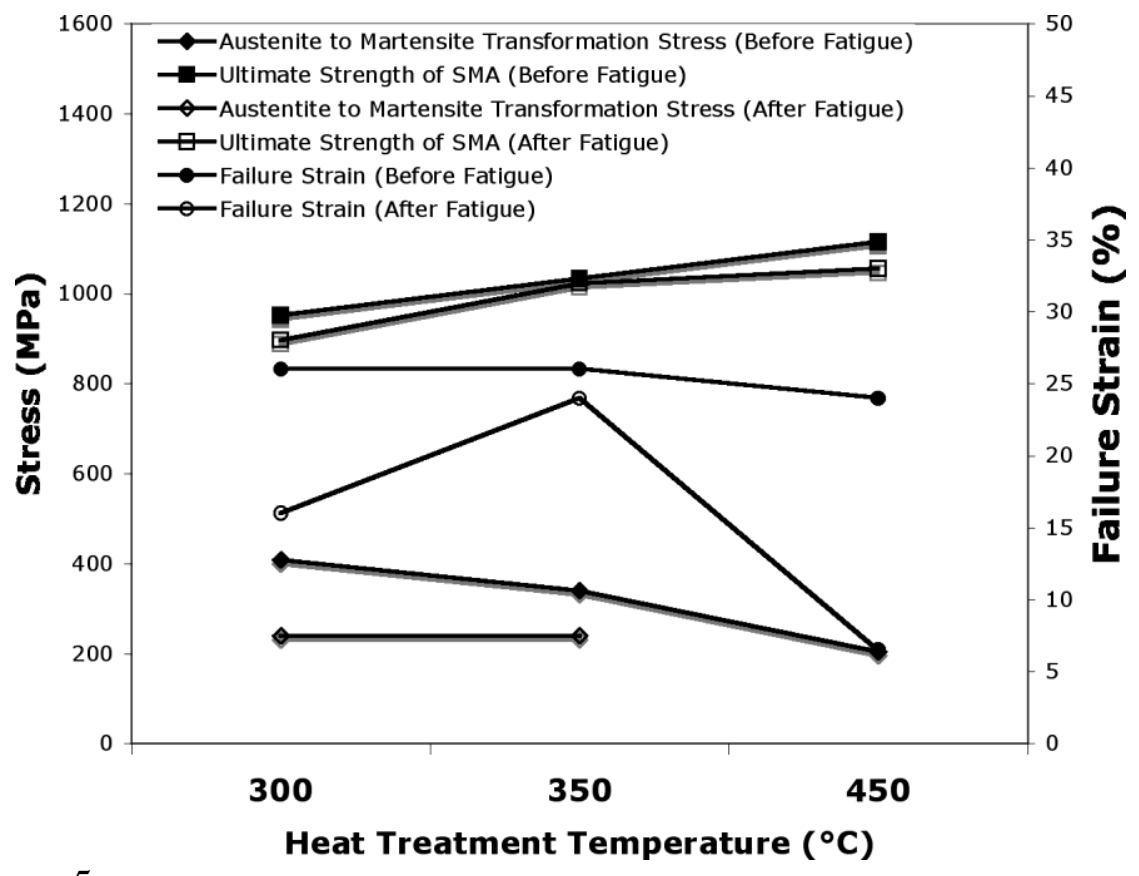

Figure 5 


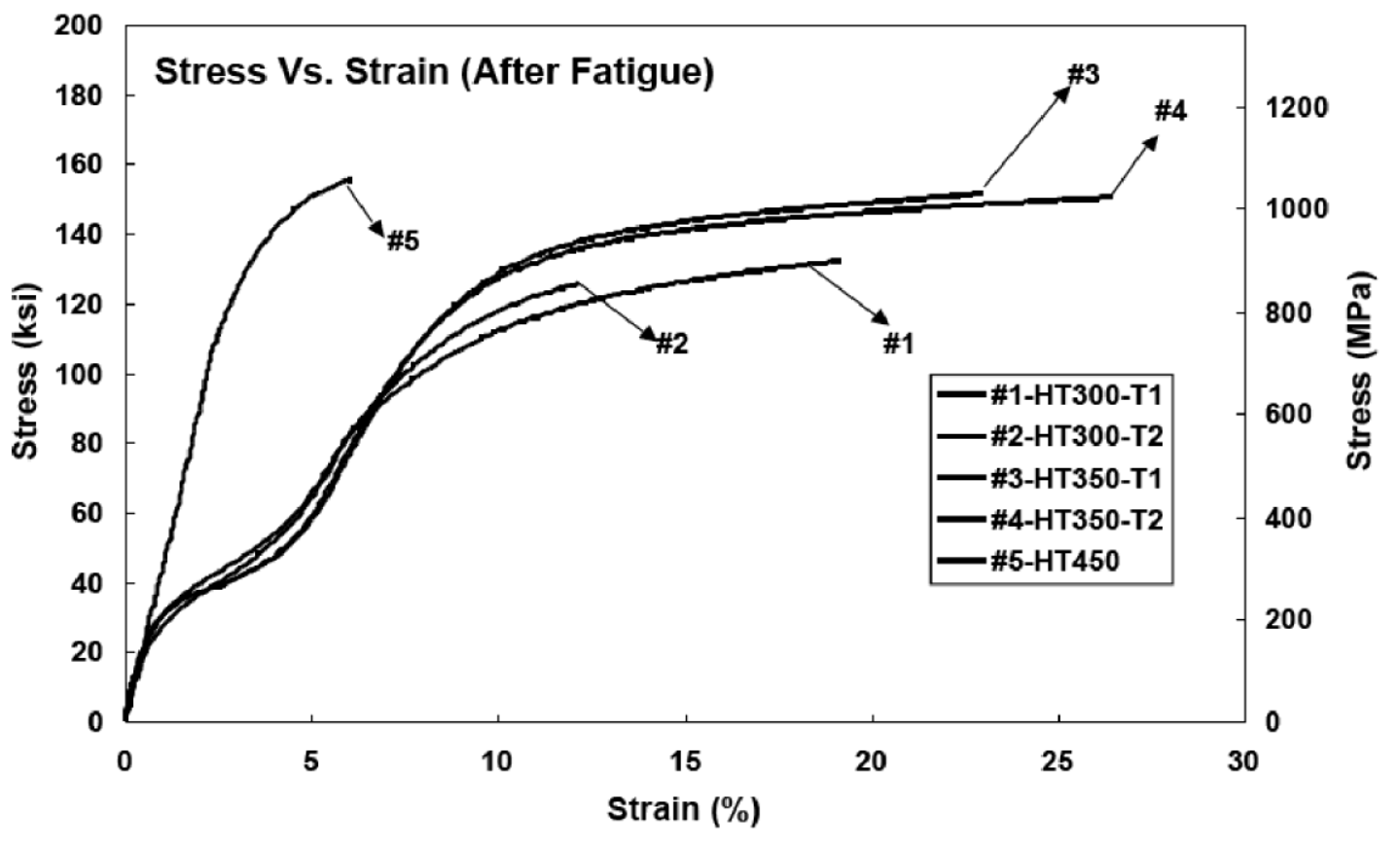

Figure 6 


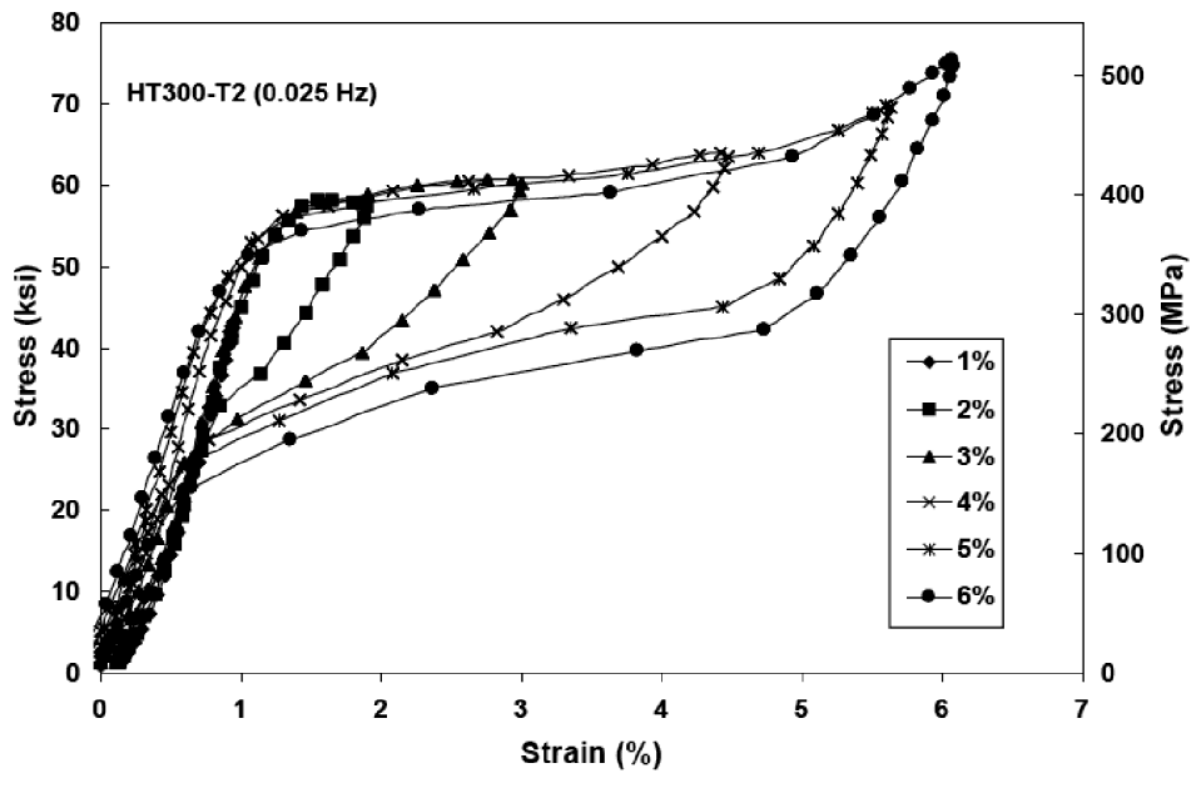

Figure $7 \mathrm{a}$

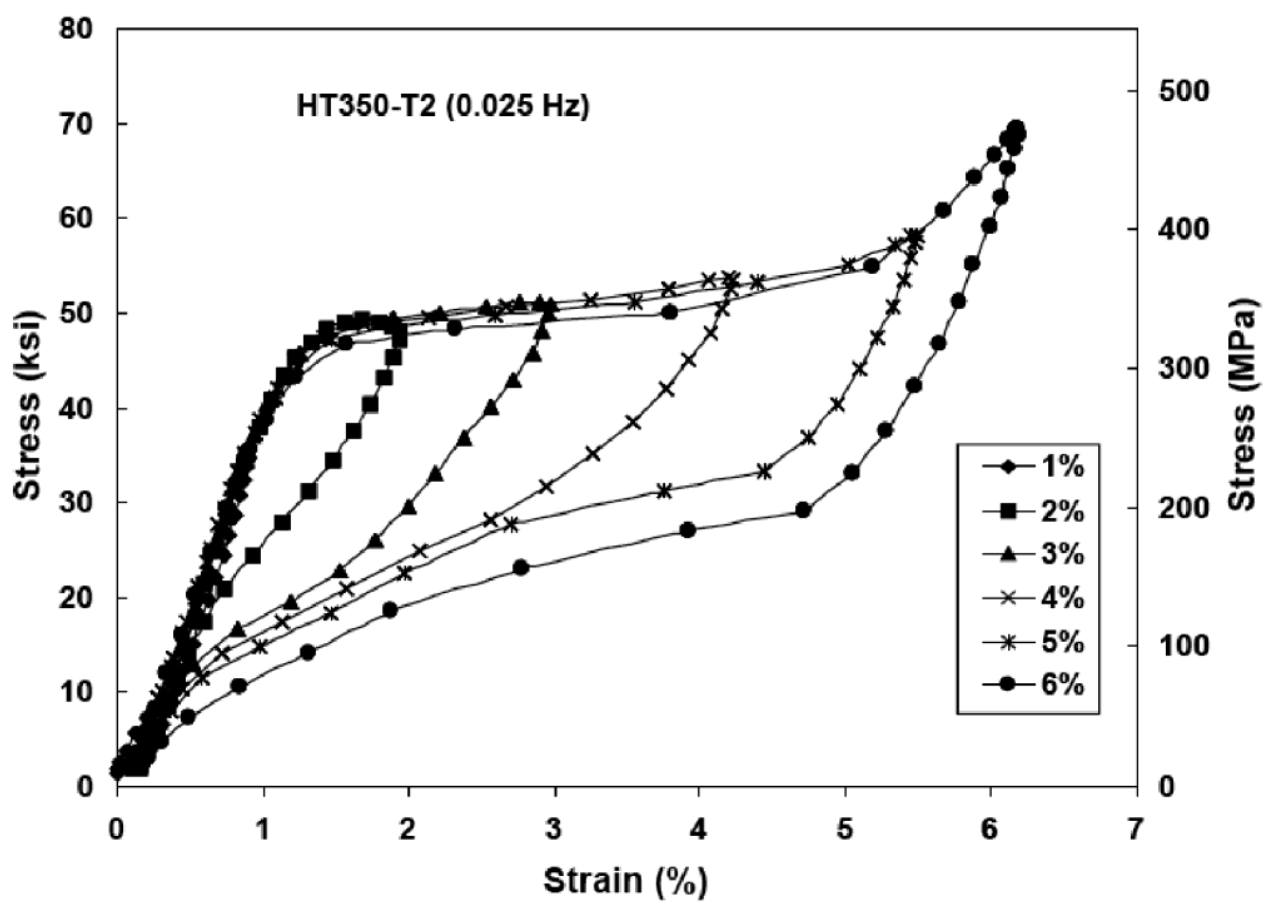

Figure $7 b$ 


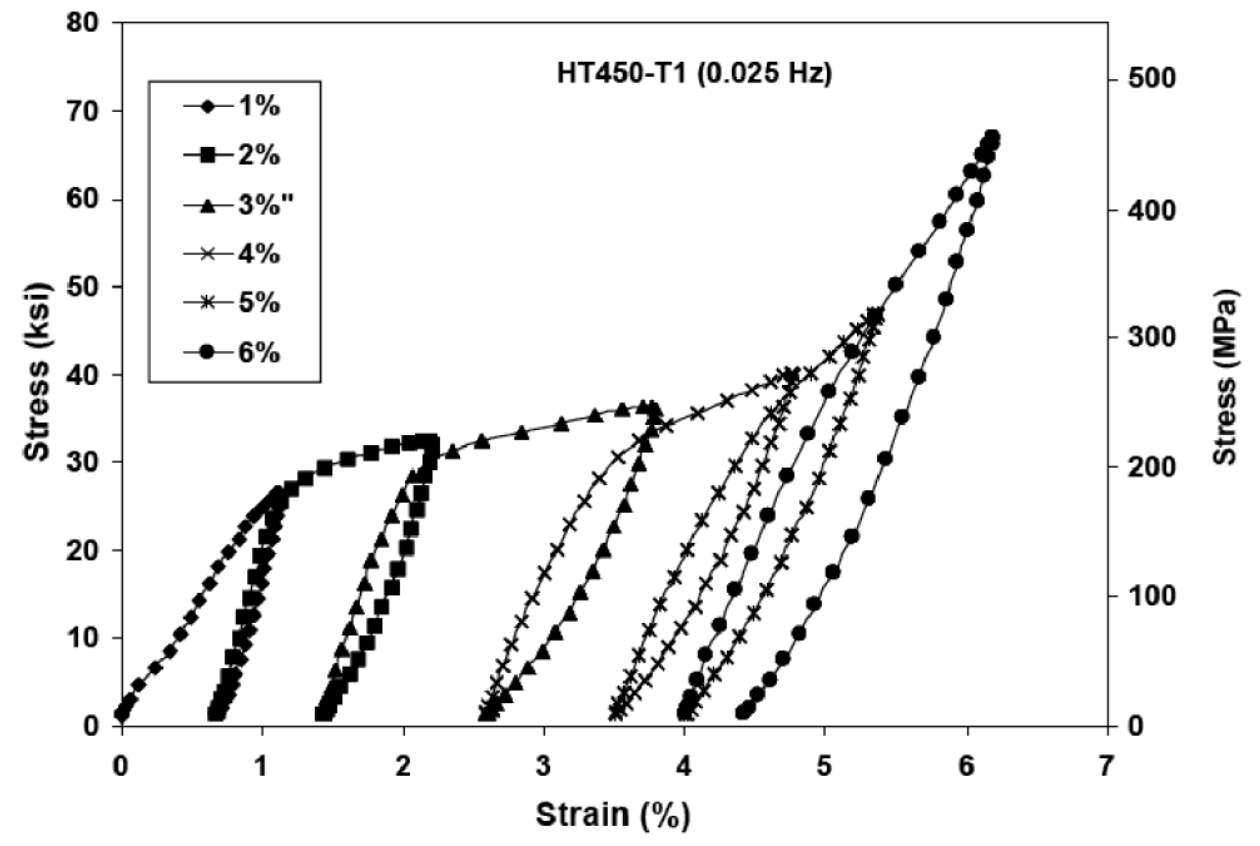

Figure $7 \mathrm{c}$ 


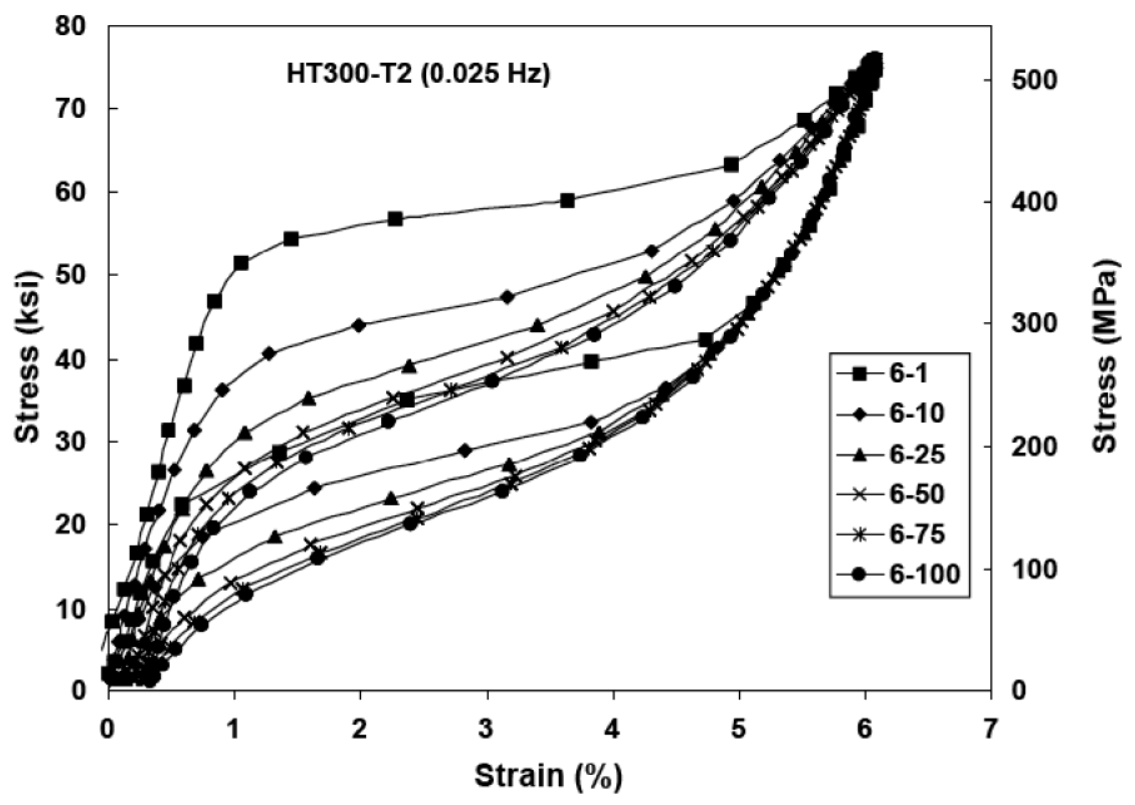

Figure $8 \mathrm{a}$

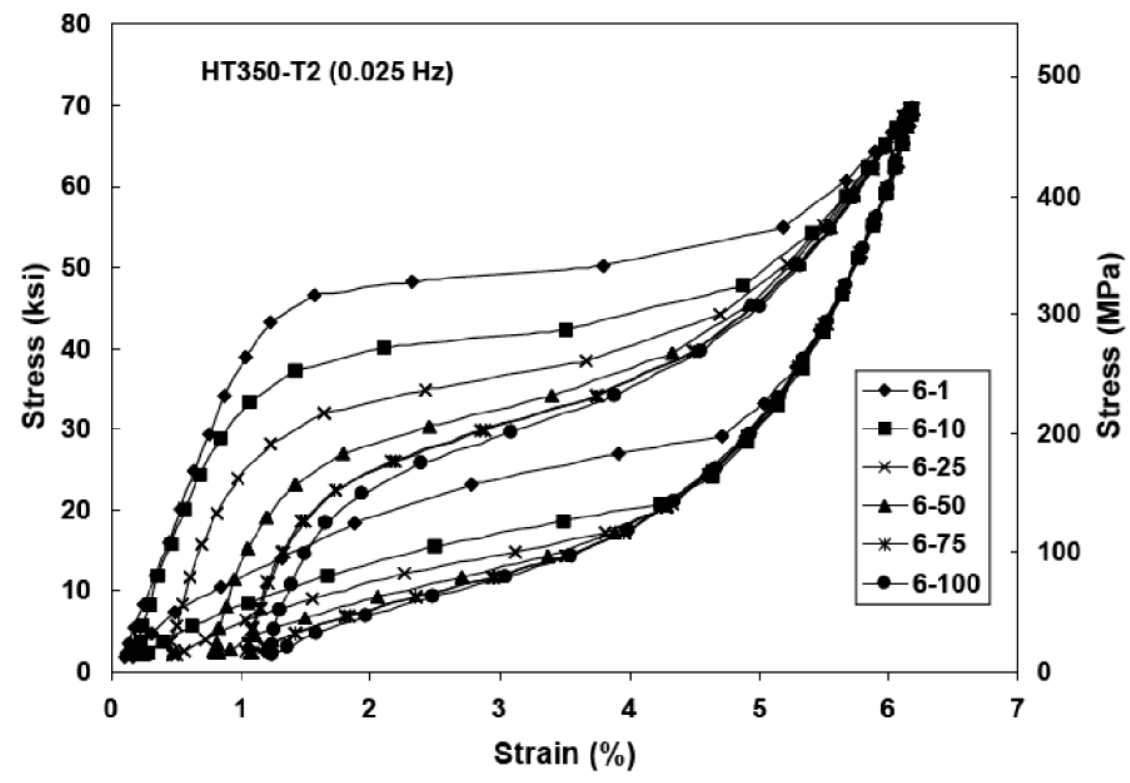

Figure $8 b$ 


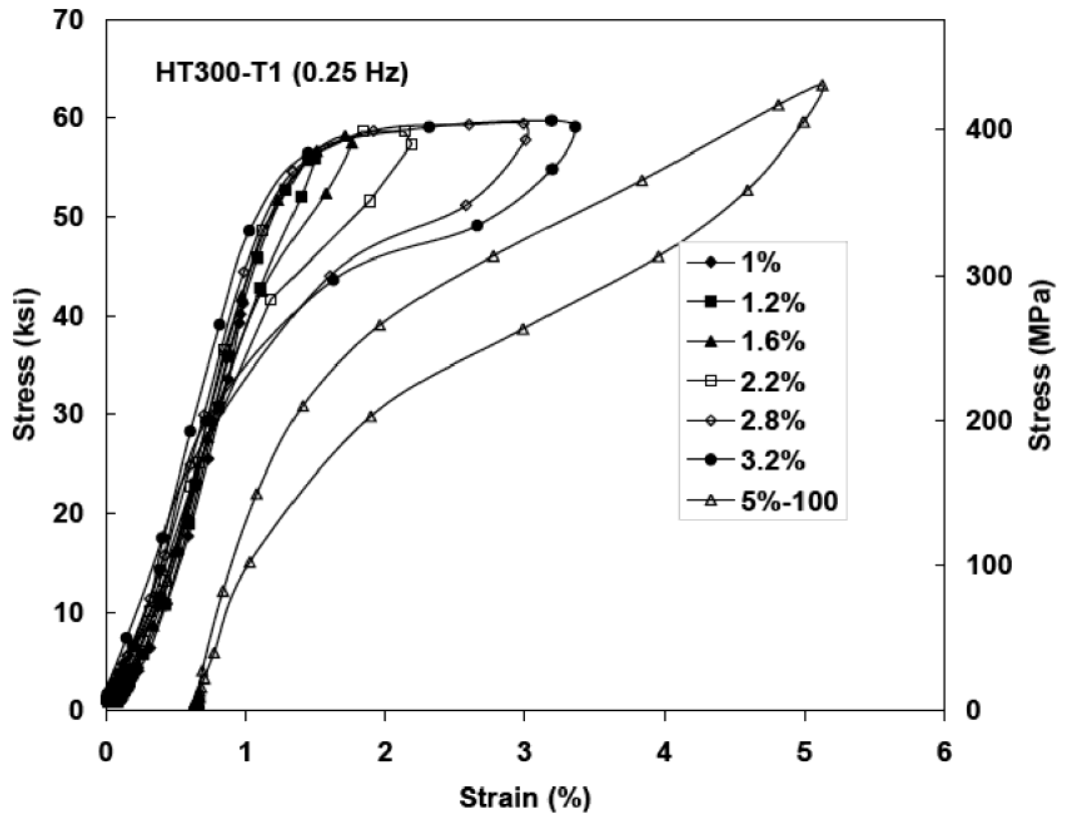

Figure 9a 


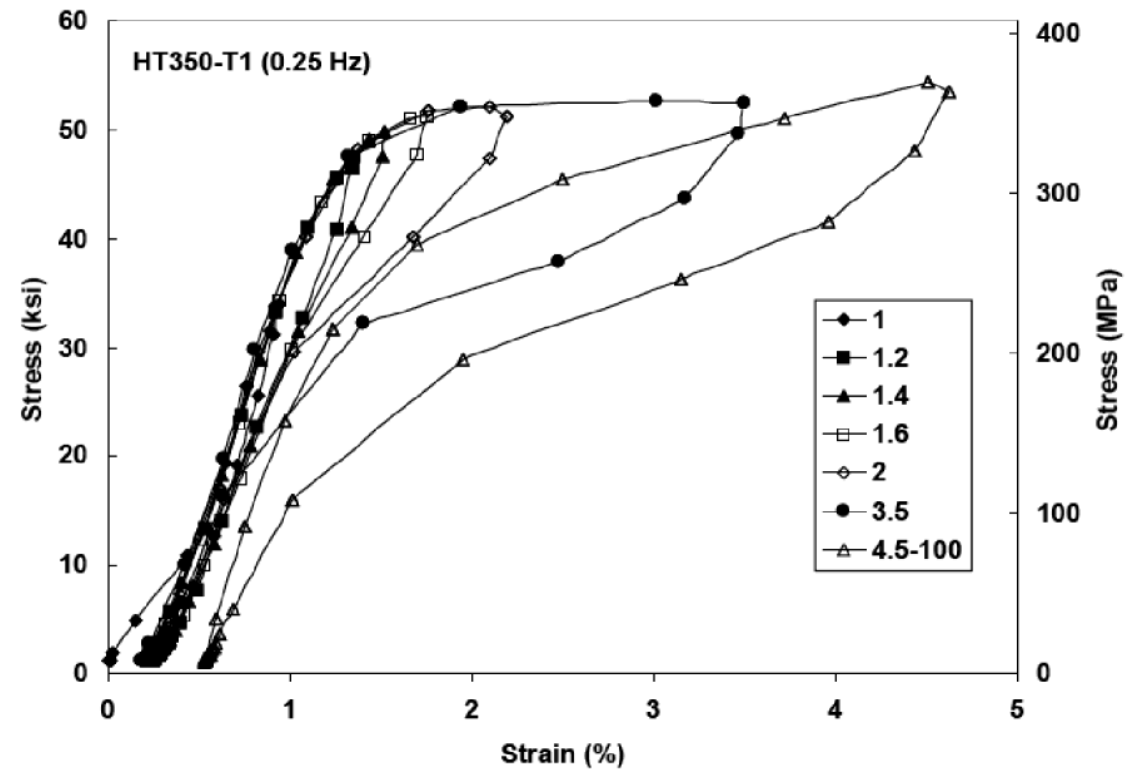

Figure $9 b$ 


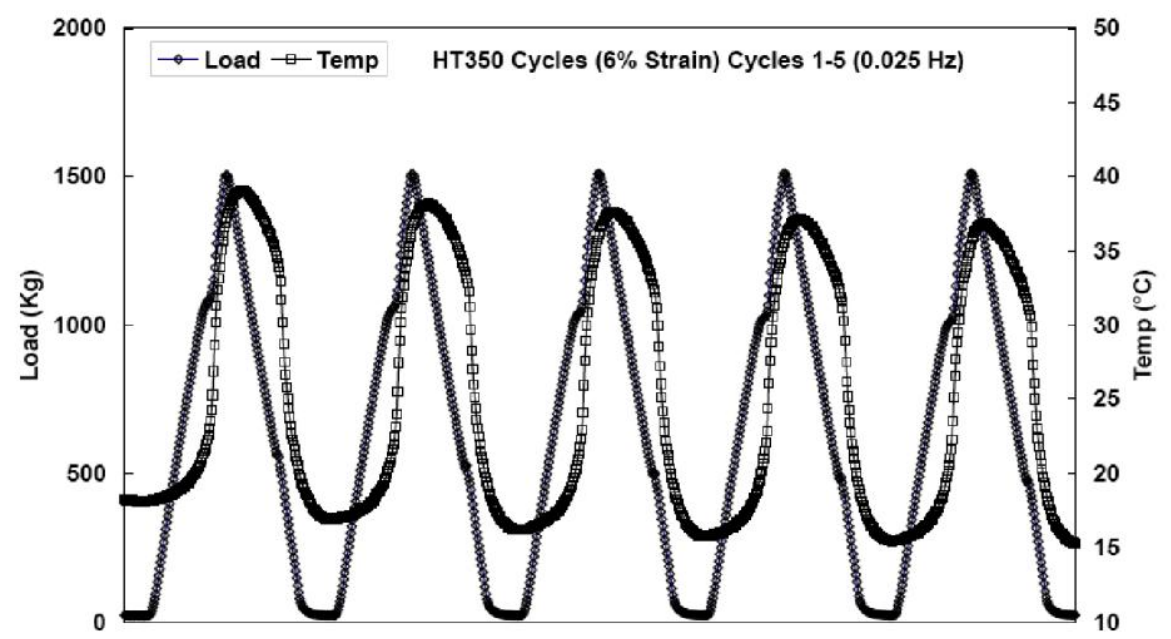

Figure 10a 


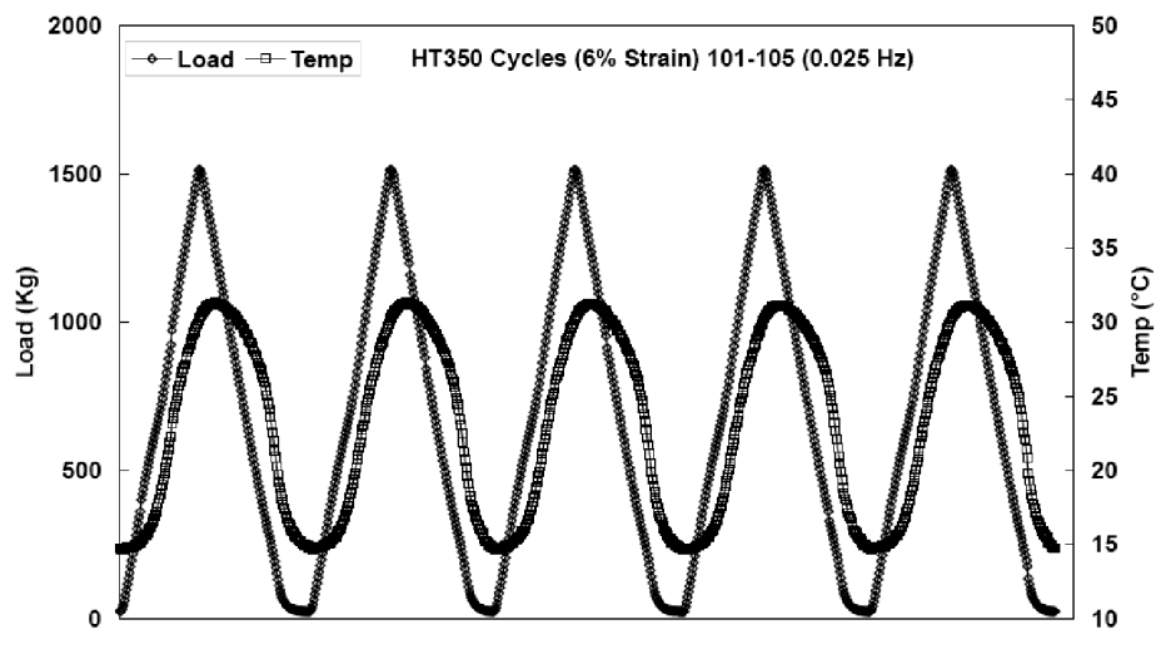

Figure 10b 


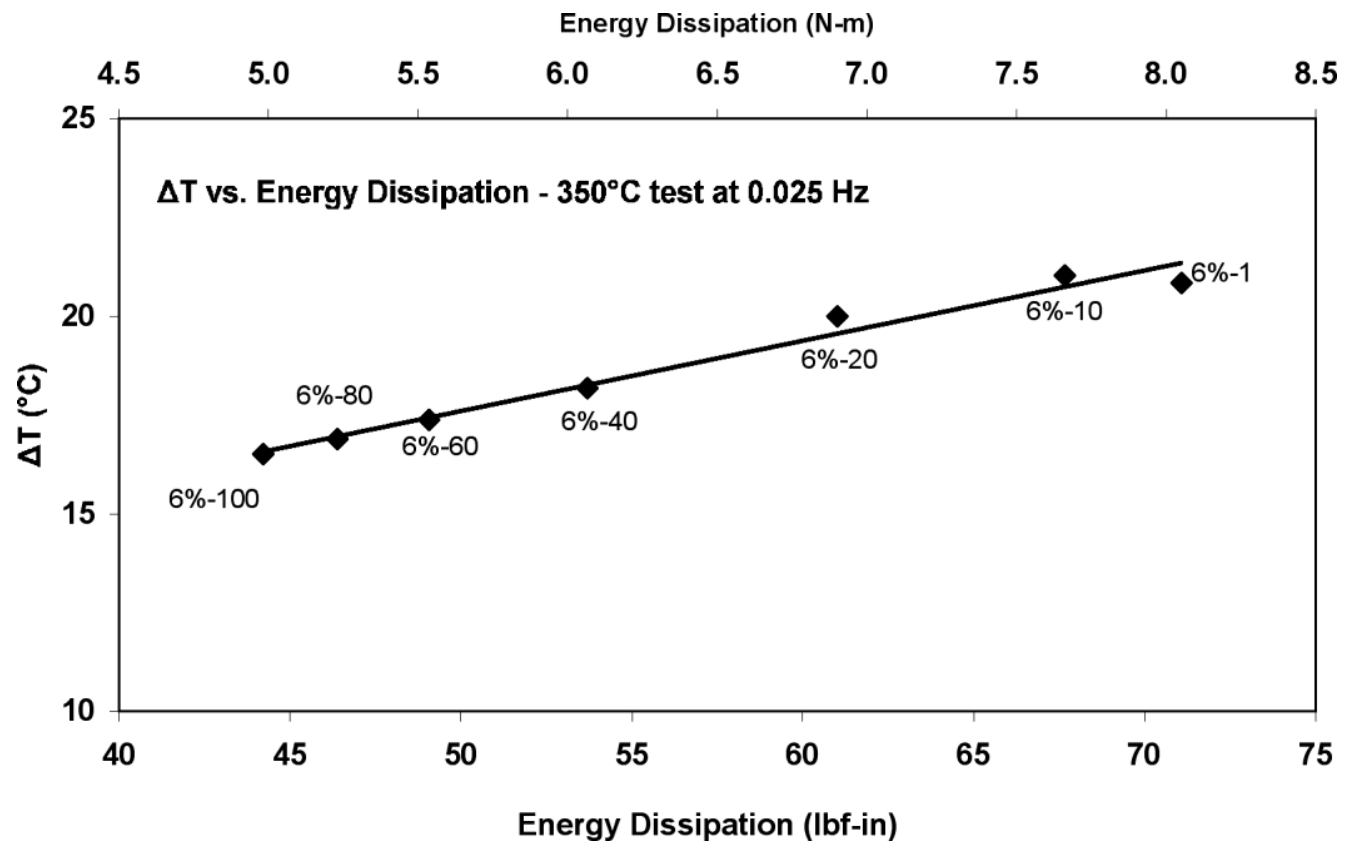

Figure 11 


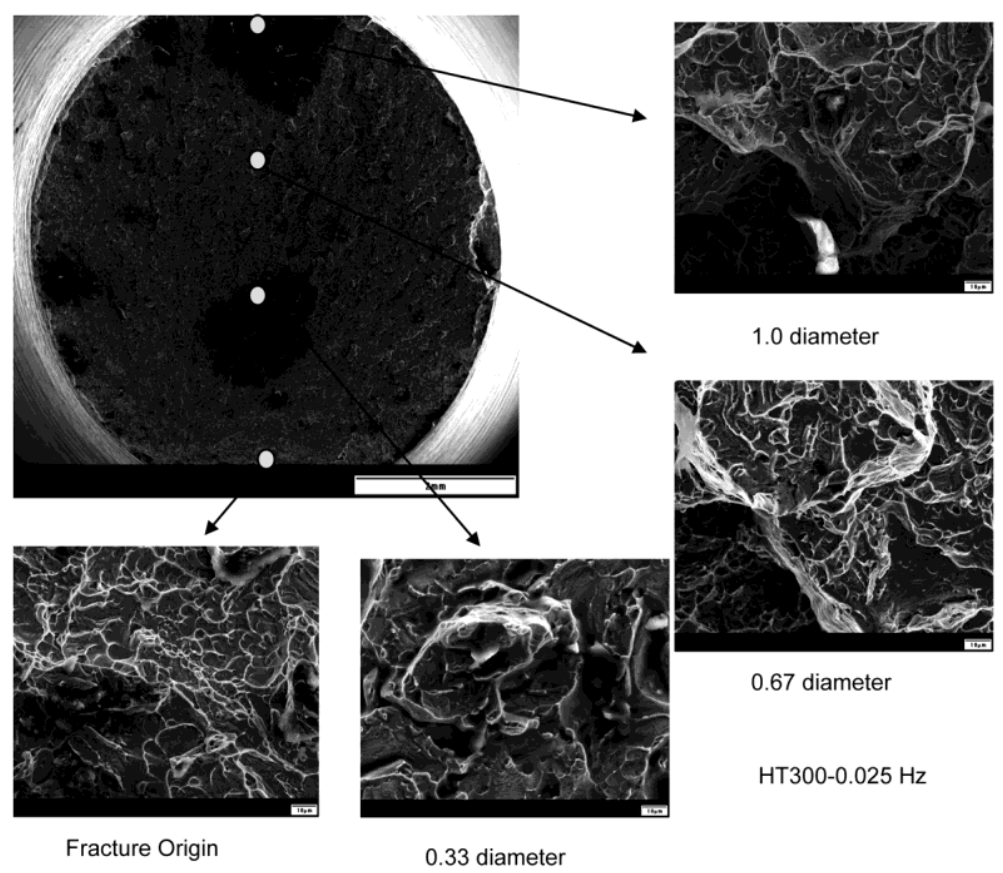

Figure 12 


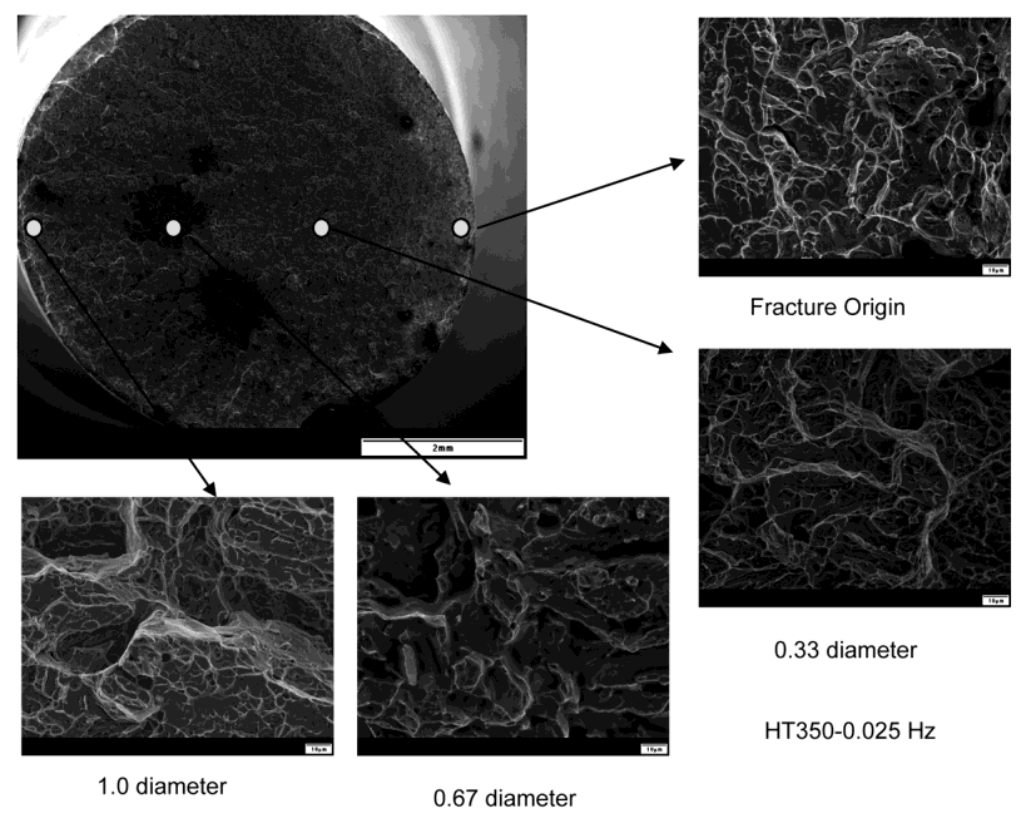

Figure 13 


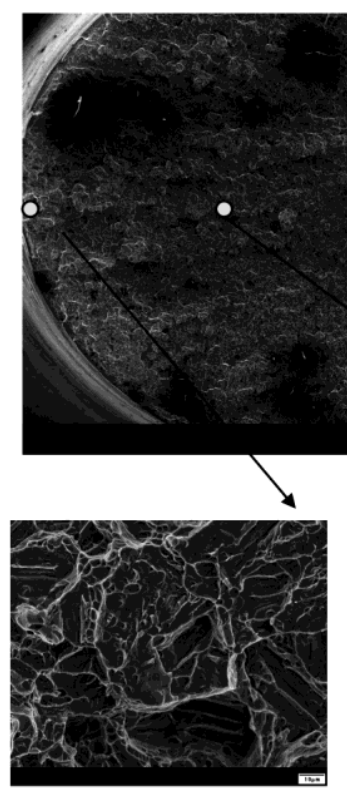

1.0 diameter
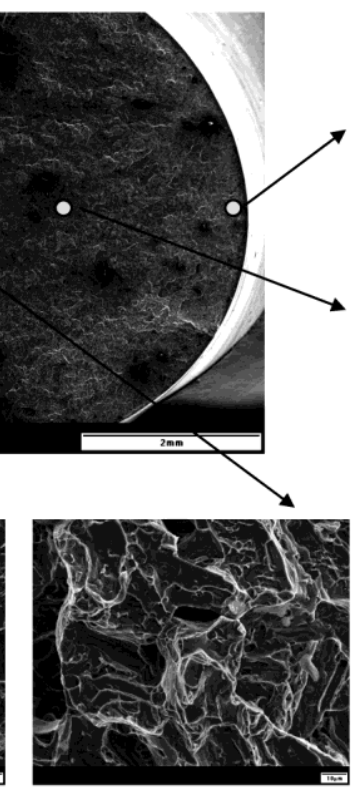

0.67 diameter

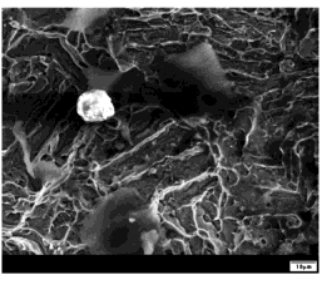

Fracture Origin

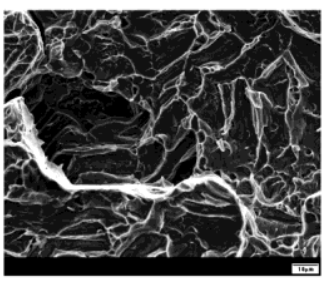

0.33 diameter

HT450-0.025 Hz

Figure 14 
Table 1 - Comparison of energy dissipation for HT300 and HT350 cyclic samples.

Calculated based on area within the Stress-Strain hysteresis plots. Frequency of testing is $0.025 \mathrm{~Hz}$.

\begin{tabular}{|l|l|l|l|l|}
\hline \multirow{2}{*}{ Cycle } & \multicolumn{3}{l|}{ HT-300 } & HT350 \\
\cline { 2 - 5 } & $(\mathrm{N}-\mathrm{m})$ & $(\mathrm{lb}-\mathrm{in})$. & $(\mathrm{N}-\mathrm{m})$ & (lb-in.) \\
\hline 1 & .12 & 1.1 & .15 & 1.31 \\
\hline 2 & .60 & 5.3 & .73 & 6.48 \\
\hline 3 & 1.72 & 15.26 & 2.37 & 20.96 \\
\hline 4 & 3.48 & 30.83 & 4.02 & 35.60 \\
\hline 5 & 5.17 & 45.74 & 6.96 & 61.56 \\
\hline 6 & 6.31 & 55.87 & 7.31 & 64.68 \\
\hline $6-10$ & 5.01 & 44.38 & 6.83 & 60.41 \\
\hline $6-25$ & 4.37 & 38.64 & 5.77 & 51.07 \\
\hline $6-50$ & 4.03 & 35.67 & 4.78 & 42.25 \\
\hline $6-75$ & 3.79 & 33.56 & 4.21 & 37.29 \\
\hline $6-100$ & 3.65 & 32.31 & 3.90 & 34.49 \\
\hline
\end{tabular}


Table 2 - Energy dissipation and temperature change for the HT350 sample. Frequency of testing is $0.25 \mathrm{~Hz}$.

\begin{tabular}{|l|l|l|l|l|l|l|}
\hline Cycle & $\begin{array}{l}\mathrm{Lo} \\
\left({ }^{\circ} \mathrm{C}\right)\end{array}$ & $\begin{array}{l}\mathrm{Hi} \\
\left({ }^{\circ} \mathrm{C}\right)\end{array}$ & $\begin{array}{l}\Delta \mathrm{T} \\
\left({ }^{\circ} \mathrm{C}\right)\end{array}$ & $\begin{array}{l}\Delta \text { Energy } \\
(\mathrm{lb}-\mathrm{in})\end{array}$ & $\begin{array}{l}\Delta \text { Energy } \\
(\mathrm{N}-\mathrm{m})\end{array}$ & $\%$ Strain \\
\hline $6-1$ & 21.7 & 28.6 & 6.8 & 16.2 & 1.83 & $3.0 \%$ \\
\hline $6-10$ & 22.7 & 29.0 & 6.3 & 18.4 & 2.08 & $3.5 \%$ \\
\hline $6-20$ & 23.0 & 29.5 & 6.5 & 19.1 & 2.16 & $3.6 \%$ \\
\hline $6-40$ & 23.0 & 30.8 & 7.8 & 20.0 & 2.26 & $4.0 \%$ \\
\hline $6-60$ & 23.0 & 31.2 & 8.2 & 20.8 & 2.35 & $4.2 \%$ \\
\hline $6-80$ & 22.8 & 31.0 & 8.2 & 21.7 & 2.45 & $4.5 \%$ \\
\hline $6-100$ & 22.9 & 30.6 & 7.7 & 20.9 & 2.36 & $4.5 \%$ \\
\hline
\end{tabular}


Table 3 - Energy dissipation and temperature change for the HT300 sample. Frequency of testing is $0.25 \mathrm{~Hz}$.

\begin{tabular}{|l|l|l|l|l|l|l|}
\hline Cycle & $\begin{array}{l}\mathrm{LO} \\
\left({ }^{\circ} \mathrm{C}\right)\end{array}$ & $\begin{array}{l}\mathrm{Hi} \\
\left({ }^{\circ} \mathrm{C}\right)\end{array}$ & $\begin{array}{l}\Delta \mathrm{T} \\
\left({ }^{\circ} \mathrm{C}\right)\end{array}$ & $\begin{array}{l}\Delta \text { Energy } \\
\left(\mathrm{lb}_{\mathrm{f}}-\mathrm{in}\right)\end{array}$ & $\begin{array}{l}\Delta \text { Energy } \\
(\mathrm{N}-\mathrm{m})\end{array}$ & $\%$ Strain \\
\hline $6-1$ & 22.2 & 27.4 & 5.2 & 15.0 & 1.69 & $3.2 \%$ \\
\hline $6-10$ & 22.5 & 28.2 & 5.7 & 16.4 & 1.85 & $3.8 \%$ \\
\hline $6-20$ & 22.5 & 29.8 & 7.3 & 16.9 & 1.91 & $4.2 \%$ \\
\hline $6-40$ & 22.3 & 29.7 & 7.4 & 17.2 & 1.94 & $4.7 \%$ \\
\hline $6-60$ & 22.3 & 29.7 & 7.5 & 16.8 & 1.90 & $4.8 \%$ \\
\hline $6-80$ & 22.3 & 29.8 & 7.5 & 16.4 & 1.85 & $5.0 \%$ \\
\hline $6-100$ & 22.1 & 29.4 & 7.3 & 16.4 & 1.85 & $5.1 \%$ \\
\hline
\end{tabular}




\section{Graphical Abstract}

Energy Dissipation and Temperature Change in Superelastic NiTi Rods
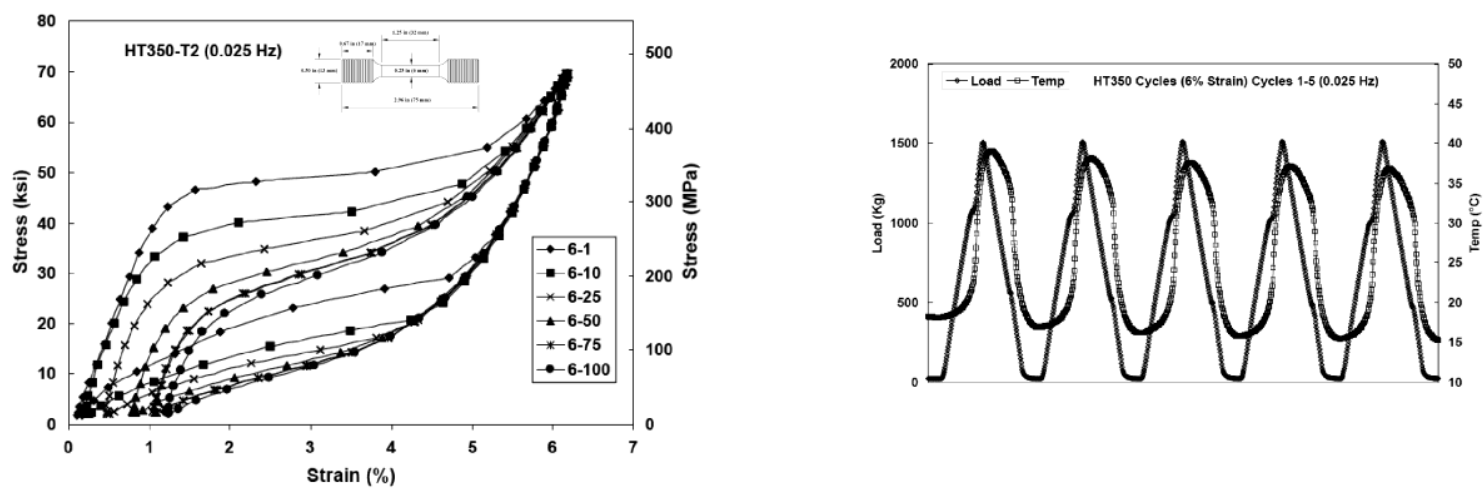

Stress Strain Behavior of NiTi

Load/Temperature Dependence

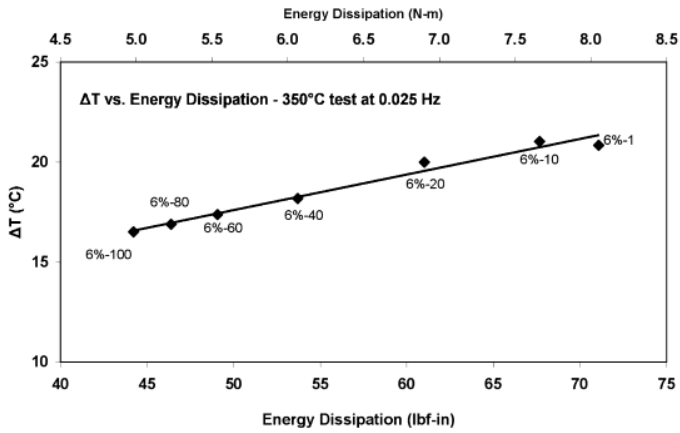

Energy DIssipation and Temperature Change 